\title{
Tetralogy of Fallot repair: Ready for a new paradigm
}

\author{
Tal Geva, MD
}

Since Alfred Blalock and Helen Taussig described the first surgical treatment option for patients with tetralogy of Fallot (TOF) in 1945, the management of this once nearly uniformly lethal disease has evolved considerably. As a consequence of seminal advances in management made during the ensuing 6 decades, early surgical mortality has decreased from $50 \%$ in the late 1950 s to less than $2 \%$ in the modern surgical era. ${ }^{1,2}$ This remarkable success story, however, is tempered by the realization that both past and current surgical management strategies still result in nearly universal residual hemodynamic and electrophysiologic abnormalities. Consequently, patients with repaired TOF face an increased mortality risk, which manifests beginning in the third decade of life and accelerates thereafter.,

Although some hemodynamic abnormalities associated with TOF repair, such as residual ventricular septal defect, are potentially avoidable, pulmonary regurgitation (PR) resulting from reconstruction of the obstructed right ventricular outflow tract (RVOT) is often impossible to avoid without residual pulmonary stenosis (PS). Although chronic PR was thought by most practitioners in the 1960s and 1970s to be a benign condition, its deleterious hemodynamic consequences have gained considerable attention during the past quarter century. ${ }^{5}$ It is now widely accepted that PR-induced right ventricular dilatation and dysfunction, left ventricular dysfunction related to adverse interactions with the volume overloaded and a dysfunctional right ventricle (through abnormal septal geometry, shared myofibers, and probably humoral factors), and electromechanical dyssynchrony all contribute to late morbidity and excess mortality late after TOF repair. ${ }^{6}$ With that realization in mind, surgeons have attempted to devise strategies aimed at relieving RVOT obstruction while preserving pulmonary valve competence. Striking an optimal balance between residual PS and PR, however, has remained elusive. ${ }^{7}$

In this issue of the Journal, Yoo and colleagues ${ }^{8}$ provide valuable information on the consequences of residual PS in

\footnotetext{
From the Department of Cardiology, Children's Hospital Boston, and the Department of Pediatrics, Harvard Medical School, Boston, Mass.

Disclosures: Authors have nothing to disclose with regard to commercial support.

Received for publication Jan 19, 2012; accepted for publication Jan 25, 2012; available ahead of print Feb 20, 2012.

Address for reprints: Tal Geva, MD, Department of Cardiology, Children's Hospital Boston, 300 Longwood Ave, Boston, MA 02115 (E-mail: tal.geva@cardio. chboston.org).

J Thorac Cardiovasc Surg 2012;143:1305-6

$0022-5223 / \$ 36.00$

Copyright (C) 2012 by The American Association for Thoracic Surgery

doi:10.1016/j.jtcvs.2012.01.076
}

patients with repaired TOF. They report their institutional experience with RVOT reconstruction in a series of 138 patients who were evaluated by echocardiography and cardiac magnetic resonance imaging at a mean age of 17 years. They retrospectively compared 51 patients who had both PR and PS (defined as Doppler maximum instantaneous gradient $>25 \mathrm{~mm} \mathrm{Hg}$ ) with 87 patients who had PR but no PS. The PR and PS group had less right ventricular dilatation and slightly higher right ventricular ejection fraction than did the PR without PS group, despite their similar PR fractions. They also noted modest correlations between higher PS gradient and lower PR fraction and right ventricular size, although the mechanism or mechanisms responsible for the observed differences in right ventricular size and function remain unclear. Yoo and colleagues ${ }^{8}$ conclude that RVOT reconstruction with "acceptable" residual PS is superior to "aggressive" enlargement of the RVOT.

Although the results of this study support the current trend among contemporary congenital cardiac surgeons to preserve pulmonary valve function as much as possible during TOF repair, ${ }^{9}$ it is important to understand that substantial gaps in knowledge persist. The retrospective, nonrandomized study design of Yoo and colleagues ${ }^{8}$ limits our ability to discern the morphologic, hemodynamic, and intraoperative variables that differed between the outcome groups. Specifically, with similar rates of transannular patch and only modest differences between groups in intraoperative right ventricular pressure and right to left ventricular pressure ratio, it is difficult to develop specific criteria for intraoperative management. Furthermore, we do not know whether the apparent advantage in laboratory values (lower right ventricular diastolic and systolic volumes and slightly higher right ventricular ejection fraction) actually translates into superior clinical outcomes. The latter question is particularly important, because our knowledge of determinants of clinical outcomes late after TOF repair is still evolving. Although studies published during the last decade have shown that severe right ventricular dilatation and dysfunction (as well as left ventricular dysfunction, regional right ventricular wall motion abnormalities, history of syncope, prolonged QRS duration ( $>180 \mathrm{~ms}$ ), and sustained ventricular tachycardia) are associated with heart failure and death, ${ }^{10-14}$ more recent data paint a more complex picture. Valente and coworkers, ${ }^{15}$ in a large, multicenter cohort study, provided preliminary evidence that right ventricular mass and mass-to-volume ratio are strongly associated with sustained ventricular tachycardia and even death late after TOF repair. In light of this information, and because a higher degree of residual PS is likely to be associated more severe right ventricular hypertrophy (which was not 
measured in the study of Yoo and colleagues ${ }^{8}$ ), we should remain cautious about adopting a strategy that favors one hemodynamic derangement (PS) over another (PR).

The ongoing quest for refinement of valve-sparing RVOT reconstruction and the unresolved debate as to the optimal balance between residual PS and PR highlight the urgent need for a new paradigm in the surgical management of TOF. Although small incremental improvements have an important role, it is now necessary to develop a bioengineered pulmonary valve substitute, as well as a contracting RVOT patch with biomechanical properties that are as close as possible to those of the myocardium. These biotechnologic leaps, which are currently being pursued by several groups, ${ }^{16,17}$ will free us from having to choose the lesser evil and bring us closer to a durable TOF repair rather than palliation.

\section{References}

1. Kirklin JW, Wallace RB, McGoon DC, DuShane JW. Early and late results after intracardiac repair of Tetralogy of Fallot. 5-Year review of 337 patients. Ann Surg. 1965;162:578-89.

2. Bacha EA, Scheule AM, Zurakowski D, Erickson LC, Hung J, Lang P, et al. Long-term results after early primary repair of tetralogy of Fallot. J Thorac Cardiovasc Surg. 2001;122:154-61.

3. Nollert G, Fischlein T, Bouterwek S, Böhmer C, Klinner W, Reichart B. Longterm survival in patients with repair of tetralogy of Fallot: 36-year follow-up of 490 survivors of the first year after surgical repair. J Am Coll Cardiol. 1997; 30:1374-83.

4. Khairy P, Aboulhosn J, Gurvitz MZ, Opotowsky AR, Mongeon FP, Kay J, et al Arrhythmia burden in adults with surgically repaired tetralogy of Fallot: a multiinstitutional study. Circulation. 2010;122:868-75.

5. Geva T. Repaired tetralogy of Fallot: the roles of cardiovascular magnetic resonance in evaluating pathophysiology and for pulmonary valve replacement decision support. J Cardiovasc Magn Reson. 2011;13:9.

6. Therrien J, Marx GR, Gatzoulis MA. Late problems in tetralogy of Fallotrecognition, management, and prevention. Cardiol Clin. 2002;20:395-404.
7. Robinson JD, Rathod RH, Brown DW, Del Nido PJ, Lock JE, McElhinney DB, Bacha EA, Marshall AC. The evolving role of intraoperative balloon pulmonary valvuloplasty in valve-sparing repair of tetralogy of Fallot. J Thorac Cardiovasc Surg. 2011;142:1367-73.

8. Yoo BW, Kim JO, Kim YJ, Choi JY, Park HK, Park YH, et al. Impact of pressure load caused by right ventricular outflow tract obstruction on right ventricular volume overload in patients with repaired tetralogy of Fallot. $J$ Thorac Cardiovasc Surg. Epub 2012 Jan 11.

9. Boni L, García E, Galletti L, Pérez A, Herrera D, Ramos V, et al. Current strategies in tetralogy of Fallot repair: pulmonary valve sparing and evolution of right ventricle/left ventricle pressures ratio. Eur J Cardiothorac Surg. 2009;35: 885-90.

10. Gatzoulis MA, Elliott JT, Guru V, Siu SC, Warsi MA, Webb GD, et al. Right and left ventricular systolic function late after repair of tetralogy of Fallot. Am J Cardiol. 2000;86:1352-7.

11. Knauth AL, Marshall AC, Geva T, Jonas RA, Marx GR. Respiratory symptoms secondary to aortopulmonary collateral vessels in tetralogy of Fallot absent pulmonary valve syndrome. Am J Cardiol. 2004;93:503-5.

12. Geva T, Sandweiss BM, Gauvreau K, Lock JE, Powell AJ. Factors associated with impaired clinical status in long-term survivors of tetralogy of Fallot repair evaluated by magnetic resonance imaging. J Am Coll Cardiol. 2004;43:1068-74.

13. Wald RM, Haber I, Wald R, Valente AM, Powell AJ, Geva T. Effects of regional dysfunction and late gadolinium enhancement on global right ventricular function and exercise capacity in patients with repaired tetralogy of Fallot. Circulation. 2009; 119:1370-7.

14. Ortega M, Triedman JK, Geva T, Harrild DM. Relation of left ventricular dyssynchrony measured by cardiac magnetic resonance tissue tracking in repaired tetralogy of Fallot to ventricular tachycardia and death. Am J Cardiol. 2011;107: 1535-40.

15. Valente AM, Gauvreau K, Babu-Narayan SV, Assenza GE, Evans SP, Gatzoulis MA, et al. Ventricular size and function measured by cardiac MRI improve prediction of major adverse clinical outcomes independent of prolonged QRS duration in patients with repaired tetralogy of Fallot. Circulation. 2011; 124:A11414.

16. Yamanami M, Yahata Y, Uechi M, Fujiwara M, Ishibashi-Ueda H, Kanda K, et al. Development of a completely autologous valved conduit with the sinus of Valsalva using in-body tissue architecture technology: a pilot study in pulmonary valve replacement in a beagle model. Circulation. 2010;122(11 Suppl):S100-6.

17. Wei HJ, Chen CH, Lee WY, Chiu I, Hwang SM, Lin WW, et al. Bioengineered cardiac patch constructed from multilayered mesenchymal stem cells for myocardial repair. Biomaterials. 2008;29:3547-56. 